\begin{abstract}
The aim of the study was to conduct a systematic review of the literature on factors that determine decision-making in Child Protection investigations. More specifically, to investigate the existing research on the four factors that are considered fundamental for child protection decisionmaking: case characteristics, caseworker characteristics, organizational characteristics and external factors. The results indicated that child welfare decisions to investigate a case and/or to implement services are influenced by characteristics of the case, the social worker and the organization, in addition to external factors. These elements work together to determine the outcome of an investigation. There are some substantial differences between various countries connected to disparities in child welfare legislation, support apparatuses, culture, ideology and socioeconomic factors. It is methodologically challenging to design studies that capture all possible variables associated with case factors, social workers and organizational factors. However, multi-level analyses of the types of variables that are most significant to case outcome conclude that caseworker assessments corresponded to organizational factors. Furthermore, decisions are better explained by characteristics of the child welfare organization than by characteristics of the social worker.
\end{abstract}

Key words: Child protection investigations, decision-making 


\section{Factors that determine decision-making in Child Protection investigations: A review of the literature}

\section{Introduction}

One of the primary tasks of child welfare services is to clarify information and make decisions in reported cases of child abuse or neglect. This is a serious task that needs to be monitored and evaluated. The Norwegian Child Protection Service (CPS) offers help and support to children, adolescents and parents who are experiencing challenges or difficulties within the family. Typically, a case starts with a note of concern, and the CPS is mandated by law to attend to any such notification and to decide whether or not there is due cause to investigate the matter further. The most common way of addressing the note of concern is to gather information from relevant sources, e.g., by contacting the family and others who know the child and the family (for example the local health center, kindergarten, school). The CPS then makes an informed decision on the basis of the above as to whether or not further action should be taken to offer assistance or services for the child and the family.. Although there is variation between countries the majority of children who receive help and support from the Child Welfare Services does so within the home of their birth parents. Examples of such home based measures that can be offered by CPS include: Guidance and advice for the family, parenting interventions, or financial support. The decision to remove the child from the home is the most serious measure to take, and is only considered in the most serious cases. If the child is considered to be in serious danger, the CPS may propose to place the child in foster care or in residential child care institutions. If the CPS decides that the child should be placed outside its birth family, the case is referred to the County Social Welfare Board. The board is a court-like organization which has the final decision-making authority based on the recommendation of the local Child Protection Services. This process of CPS work is similar in many countries, and commonly referred to as the child protection funnel (Miller-Perrin \& Miller, 2012). 
In Norway, evaluations of the practice in the child protection services have been conducted by The Norwegian Board of Health Supervision (2012) and the Office of the Auditor General of Norway (2012). Both of these evaluations have pointed out shortcomings in child welfare assessment and decision making. The main concern was that decisions were made without seeing the child. Furthermore, in several instances cases were dismissed although the report indicated a serious concern for the child. Internationally, the same critique has been raised. As Munro (2011) pointed out interpreting and responding to referrals regarding children potentially at risk of harm is a complex task that no team or individual can be expected to make the 'right' judgement of in every case. Therefore, it is important that child protection work is organised in a manner that maximise the quality of case processing and decision making. Higgins (2015) identifies several criticisms of the current approach to child protection social work in England. The key message is that contemporary child protection adopts a narrow approach to child welfare and the role of social work (Higgins, 2015). Schreiber and colleagues (2013) detected several factors that impaired the parent involvement in child protection decision making, such as high caseloads that limit the amount of time spent with the service users, policies and procedures that place heavy demands on paperwork instead of relationships with clients, as well as the high pressure nature of the cases (Schreiber, Fuller \& Paceley, 2013).

Baumann, Dalgliesh, Fluke and Kern (2011) have developed a theoretical framework in which knowledge from decision-making theory is specifically used in a child welfare context, i.e. the Decision-Making Ecology (DME) model. The theory is based on the idea that, when child welfare services make a decision, the outcome of that decision is dependent on characteristics connected to the child's circumstances, the parents' care-giving skills and resources in the local environment. The DME model considers child welfare decisions to be a function of case (e.g., type and severity of maltreatment, risk, poverty), decision maker (e.g., experience, values), organizational (e.g., policy, workload, resources), and external characteristics (e.g., critical events, funding) (Fluke, Baumann, Dalgleish, \& Kern, 2013). Because decisions related to child welfare assessment are made in an 
organizational context, in which the child protection services (CPS) agency is regulated by law and managed by available resources, it follows that organizational and external factors also influence the decisions that are made, and additionally how the situation is interpreted and understood by social workers.

Insert figure 1 here.

In a theoretical analysis, Helm (2011) argues that analysis of information in a child welfare case is a complex task and that, when such analysis lacks a theoretical foundation, it threatens the quality of decisions. Group-based decision making is therefore discussed as a solution to interpretation bias in the individual social worker. Time and resources for social workers to work in teams and learn from their mistakes is presented by Helm as a definitive factor in developing sound clinical judgment and maintaining quality in analyses and assessments. In another theoretical analysis, Burton (2009) also claims that having a «learning culture» in the organization is necessary to maintain good quality in decisions that demand clinical judgment. The author points out that a common cause of erroneous decisions is that there is a tendency to ignore or reject new information when it does not resonate with original assessments. Thus, social workers must have a reflective and self-critical approach to the analysis of information in child welfare cases. This must be facilitated at the organizational level, Burton concludes. Kirkman and Melrose (2014) went through the literature on decision-making theory and identified four factors that reduced the quality of social workers' decisions in child welfare cases. These included: (i) time pressure and case load, (ii) individual bias, (iii) decision-making fatigue and (iv) quality of information.

Little is known about the quality of the work within the child protection services, both when it comes to the proportion of dismissed referrals (Lurie, Kvaran, Tjelflaat \& Sørlie, 2015) and the manner in which inquiries and inspections are carried out (Vis, Storvold, Skilbred, Christiansen, \& Andersen, 2014). There are however some factors that are considered to be significant in the 
decision-making process within the child protection services, i.e., the case, the caseworker, the organization, and external factors. The current study was therefor set up to explore these factors.

\section{Aim of the study}

The aim of the study was to conduct a systematic review of the literature on factors that determine decision-making in Child Protection investigations. More specifically, we wanted to investigate the existing research on the four factors that are considered fundamental for child protection decision-making: case characteristics, caseworker characteristics, organizational characteristics and external factors.

\section{Method}

The review process consisted of identification, selection, coding, categorisation and summary of international publications on child welfare investigative work.

\section{Identification of publications}

The search for publications has been carried out using three different approaches. First, an electronic search using databases of research literature, followed by a search of websites and, lastly, a manual search in literature lists.

The search objective was to identify literature that sheds light on all sides of child welfare assessment, from the time a referral is received, and the first risk assessments are performed, to the time inquiries are initiated and decisions made. Thus, broad searches in the Psycholnfo database (Ovid) and SocialCareOnline database has been done. Two separate search strings were developed for those databases. The first string developed for Psychlnfo contained 71 keywords and 25 words linked to subject headings in the database. There were two main types of search words, the first group were selected to identify studies about children in contact with child protection services. The second group were selected to identify studies about decision-making. The complete search string combined these keywords and subject headings through 36 search-lines. Number of hits for each line 
were recorded. At most the search for studies about children in contact with social services yielded 56817 hits and search for studies about decision making yielded 655630 hits. The combination of these two groups of search words yielded 6360 hits when limited to studies from 2005 and onwards. A more limited search was done using the database, SocialCareOnline. This search was particularly directed towards identifying models for investigative work and decision making. The search contained 11 search words (i.e., child abuse, neglect, child protection, decision making, assessment), and yielded 500 hits. In addition the Nordic database, Norart, provided 5 hits. Using the open Net via «Google.no» and Scandinavian websites identified a total of 13 additional publications. Through a manual review of literature lists in publications that were identified in the systematic searches, and by contacting colleagues, 7 new publications were singled out. The complete search strings from each of the databases are available from the first author upon request.

\section{Selection of publications}

The literature searches revealed 6,900 publications potentially being relevant. The publications were reviewed and assessed in a stepwise process based on the pre-defined inclusion and exclusion criteria. The most important inclusion criteria were that the study had to deal with child welfare work and be related to the decision-making process of child welfare assessment. In this selection process, a synopsis was also created outlining themes that were excluded from the summary. A complete synopsis of inclusion criteria and excluded themes is provided in Table 1.

-insert Table 1 here

\section{Procedure}

First, all titles were evaluated. Based on the titles, publications that clearly did not meet the inclusion criteria were excluded. Thereafter, the remaining $(N=609)$ publications were reviewed and more closely scrutinized in relation to the inclusion criteria. This resulted in the selection of 220 
publications for complete text assessment. After full text review, 111 publications were coded and included in the study. Seven additional publications were identified and coded through a manual search of literature lists. After coding the 118 publications, 34 publications were identified exploring factors related to decision-making and included in this review. A synopsis of the selection process is presented in Table 2 .

- $\quad$ Insert Table 2 here

In selecting articles at the title level (step 2), and reviewing the publication summaries (step 3), $10 \%$ of the publications were evaluated by two researchers, independent of each other. At step 2 there was $93 \%$ agreement and at step 3 the interrater agreement was $71 \%$. On disagreement over inclusion at step 2, the publication was included. Disagreement at step 3 led to discussion between the researchers until a consensus was reached. At step 4 all of the studies were examined by two researchers. At step 6 all of the studies were coded by two researchers. Publications that were included in this review were coded with respect to place of origin, type of publication, method, study topic and the main conclusion for the study. A complete synopsis of the codes/search string can be obtained by contacting the authors.

\section{Results}

This presentation of significant factors in decision-making adheres to Baumann's categorisation (see Figure 1). The significance of 1) case characteristics, 2) factors associated with the social worker and 3) factors connected to the organization of services are further presented. In terms of 4) external factors, there were no studies detected that had this category as a main focus. This means that even though some studies addressed several factors, including external, all of the identified studies were included in one of the other three categories by the researchers who coded them.

\section{Significant case characteristics}

There was a total of 14 studies that had looked more closely at case characteristics related to dismissal after investigation. There were some recurring factors across cases that proved to have a 
bearing on whether or not cases were dismissed. The most important factors that came up in the studies were the family's ethnic background, characteristics of the children (e.g. gender and age), substance abuse among the parents and the parents' socioeconomic status. These findings are summarized below.

A main finding across the American studies was that cases with children of African-American background were less likely to be dismissed and that African-American children were overrepresented in placements outside the home. Johnson, Clark, Donald, Pedersen and Pichotta (2007) reported of a $36 \%$ greater chance that the caseworker would recommend removal from the home in cases with families of African-American background than with those of the Caucasian race. Cases with indigenous people had $73 \%$ less likelihood of a recommendation for placement outside the home. In a register study of 186,182 cases in Texas, Detlaff and colleagues (2011) found that race was a predictor for whether cases should be investigated or dismissed. Cases with children of minority families had a lower likelihood of being dismissed. Rivaux and colleagues (2008) also investigated whether decisions were influenced by race and poverty, discovering that children of African-American families were placed in foster homes to a greater degree than children of other backgrounds. Jones' (2015) study of work processes in case management in Minnesota found that reports of cases with minority families had greater probability of being investigated.

Cross \& Casanueva (2008) found that the child's age and gender were of significance $(N=$ 4515). Cases where the child's gender was male were more frequently dismissed than cases involving the female gender and cases with children aged 6-10 were more seldom dismissed than cases involving both younger and older children.

In Canada, Williams and colleagues (2011) discovered that the primary caregiver's substance abuse, in addition to proven exposure to drugs/alcohol for the child after birth, had the greatest significance for further investigation. Additionally, exposure to violence in the home reported by the police and physical injury as a result of abuse were important predictors for cases not to be 
dismissed. Less serious abuse or neglect was associated with dismissal to a greater degree.

Scannapieco and Connell-Carrick (2005) discovered that poorer parenting skills, lack of impulse control and use of strict discipline were predictors for case investigation. In his doctoral dissertation in the USA, cases with reports of substance abuse were less likely to be dismissed (Howell, 2010).

In Sweden, a study looked more closely at the process of child welfare work from investigations to decisions (Östberg, 2010). All reports about children from 0 to 19 years old in contact with two social welfare offices during a 2-month period were assessed $(N=260)$. The results showed there was a high probability of further investigation for referrals that dealt with suspected abuse. Furthermore, the likelihood of an investigation being conducted was higher if the report came from professionals (not the police) and if it pertained to a girl (Östberg, 2010).

In a study based on the Canadian national register of child welfare cases the most important case characteristic that led to a case not being dismissed was if the referral came from the police (Trocmé, Knoke, Fallon \& MacLaurin, 2008). Moreover, Trocmé and colleagues saw that cases with several forms of neglect were less frequently dismissed. They additionally discovered that risk factors among parents, living situation and the seriousness of the risk of harm were significant to whether or not the case was further investigated. In another Canadian study based on the same set of data, it was found that family poverty did not influence the caseworkers' decisions on whether to dismiss the case when a concern was reported due to suspected caregiver violence (Moraes, Durrant, Brownridge \& Reid, 2005). Fallon, Ma, Black and Werkerle (2011) discovered that there were some unique characteristics among young parents investigated by child welfare services in Canada. Often they had multiple problems such as poverty, poor living conditions, mental health problems, violence and concerns about the child's comportment. In Israel, Jedwab and colleagues (2015) have studied which case characteristics led to the dismissal of cases. They found that non-dismissal was associated with socioeconomic background, parents' health, previous contact with child welfare, characteristics of the referral, medical findings and parents' behaviour (Jedwab et al., 2015). 
In a Norwegian doctoral dissertation (Juul, 2010) child welfare's investigations of referrals were studied. The dissertation was based on a study of case documents from child welfare investigations of nine cases, along with interviews of caseworkers, children and parents in the same cases. Juul found that the caseworkers rely heavily on their knowledge of psychology and that they collect information on the parents' childhood and family interaction in addition to individual descriptions of children and parents. Information on socioeconomic factors was collected to a lesser degree.

The results on case characteristics are summarized in Table 3.

- $\quad$ Insert Table 3 here.

\section{The significance of the social worker to the quality of child welfare decisions}

There were 11 studies that dealt with the social worker and his or her significance to the quality of child welfare investigative work. This includes assessment of thresholds for intervention, possible sources of error associated with the social worker, the focus of the social worker, organizational factors and external factors that are thought to influence the social worker's decisions.

In Australia, case files connected to all child welfare cases that were closed in the course of a 9-month period were reviewed. In all, this comprised 407 custody cases that involved 622 children. Additionally, interviews were carried out with 155 social workers. The results demonstrated that the social workers assessed four different dimensions. The resonance of the caseworkers is described as a 4-step process whereby the child's custody situation is assessed first. Next, the parents' capacity to change is assessed, followed by the severity of the case and, lastly, the quality of case documentation. In a qualitative study of the decision-making process of social workers in less serious cases (Platt, 2006) it was concluded that social workers managed the complexity and uncertainty of referred cases by breaking down the complexity into the following five categories: (i) how specific the report is, (ii) how great the child's exposure to risk is deemed to be, (iii) how credible the parents are, (iv) the degree to which the allegations can be confirmed and ( $v$ ) the severity of the case. 
Wilkins (2013) performed a qualitative vignette study based on interviews with 18 caseworkers to examine how child welfare services analysed information in cases where severe neglect was suspected. The study concluded that the participants were capable of using the given information to provide coherent and analytical reasoning but that there was a weakness in the analyses when it came to weighing protection factors against risk factors. The author argued that this speaks favourably to the use of validated risk instruments together with judgment in assessing reports.

Lazar (2006) discovered that social workers' assessment of the severity in cases involving child abuse were influenced by social workers with authoritative personality types as well as the gender of the child and the caseworker. Social workers with an authoritative personality deemed cases more serious and recommended more extensive child welfare intervention. Social workers assessed abuse and sexual abuse of boys to be less serious than corresponding cases involving girls. Female social workers deemed abuse of girls as less serious than did male caseworkers.

Jent and colleagues (2011) analysed social workers' assessments of what the threshold is for physical child abuse based on their evaluation of pictures of various types of injury and marks on children. The results demonstrated agreement among American social workers on what was considered as abuse. The assessments were nonetheless influenced by the social workers' attitudes on how acceptable it is to use physical punishment in raising children, as well as the ethnicity of the social worker. A corresponding Canadian study did not find such effects (Stokes \& Taylor 2014).

An American study (Berger, McDaniel \& Paxon, 2005) that looked at the correlation between caseworkers' and clients' ethnicity found discrepancies in the assessments of caseworkers of colour versus white caseworkers when interacting with families of colour and white families. This goes against the idea of matching social workers' ethnicity to that of the family and promotes the use of multiple interviewers in assessing parenting competence. A vignette study involving caseworkers (Proctor \& Azar, 2013) examined stereotypes of mentally disabled parents. The result demonstrated 
that the caseworkers felt sorry for and were more willing to offer support services to parents who were mentally-disabled, in addition to showing less anger and contempt. The study found, however, that this was not significant to the caseworker's recommendation in relation to child custody.

Caseworkers' stress level has proven to influence their assessments of risk in cases involving possible removal from the home. In a survey on how parents' behaviour when interviewed during the investigative process influenced caseworkers' stress levels (LeBlanc, Regehr, Shlonsky \& Bogo, 2012), fictitious interview situations were arranged in which caseworkers met with actors who demonstrated either a confrontational or welcoming manner. The result showed that the parents who were confrontational increased the caseworkers' stress level. Caseworkers' competence was an important topic in an American study conducted by Lee, Sobeck, Djelaj and Agius (2013). They discovered that many child welfare staff did not have enough experience or confidence in the role of social worker when they were meant to assess concern in relation to new cases that came in. Based on the findings in this focus group study of 39 social workers, the authors concluded that longitudinal training and guidance could increase the decision-making competence among social workers, in addition to making them more confident in the decision-making process. They additionally recommended implementation of an evidence-based tool to assess risk that had been shown to effectively improve assessment of risk.

In a qualitative Canadian study of 23 master students in social work, Tufford, Bogo and Asakura (2014) found that the focus was largely on the parents. When interviewing parents they were primarily concerned with the parents' problems. In New Zealand some similar results were found in a qualitative study of the decision-making processes of social workers (Kedell, 2011). The main conclusion of this study was that decisions are a result of a negotiation process in which morals, identity, relations and knowledge about risk play together in a reflexive process where different caseworkers place weight on different things. A common factor all of the caseworkers in this study, 
however, was that they emphasized the parents' care competence more than other services for children at risk.

The results on social worker characteristics are summarized in Table 4.

- Insert Table 4 here.

\section{The significance of organizational factors in the quality of child welfare} decisions.

The way in which the services are organized can have significance for judgments, for which case characteristics are weighed most heavily and, therefore, for the quality of child welfare investigative work as well. In the following section, main findings of the 9 articles dealing with organization are summarized.

In 2015, Font and Maguire-Jack published a study focusing on Baumann's decision-making ecology model (DME) (Baumann et al., 2011). In this American study they examined whether risk factors tied to family conditions and the use of decision-making models were associated with dismissal. The results showed that characteristics of the individual child welfare offices, such as available services and resources, were of considerable significance in deciding whether to dismiss or investigate further. Characteristics of the individual child welfare services, however, were not associated with decisions to place children outside the home. Characteristics of the child, the county of residence, the caseworker, and acute danger for the child indicating immediate removal were associated to a lesser degree with dismissal than characteristics of the child welfare office and risk factors in the family (Font \& Maguire-Jack, 2015).

In a multi-level Canadian study of factors tied to the decision to initiate child welfare services after report investigations, it was found that factors associated with the parents and the household were of greater significance than the needs of the child and the status of the child's care in decisions on whether or not to offer services (Jud, Fallon \& Trocme, 2012). 
In Great Britain, Platt and Turney (2013) published a study looking at thresholds in child welfare decision-making processes and which factors were significant to the opening of a case versus dismissal of a report. The conclusion was that thresholds for what is considered to be a child welfare case are influenced by the type of report made on the child, policy and organizational factors, collaboration between various agencies and the social worker's own judgment (Platt \& Turney, 2013).

An American study (Steen \& Duran, 2014) examined whether the organization of referral management was significant to dismissal rates before and after investigations in 44 states. The study found that states with decentralized reporting systems, which means that referrals are sent to the specific child welfare office, had significantly higher (10\%) dismissal rates than those with a centralized system where all referrals go to a governmental reception centre. However, there was no difference in the percentage of cases that were dismissed after the investigation was completed. Janczewski (2015) analysed whether there was any disparity in dismissal rates between districts that only investigated cases with the idea of determining whether children were suffering neglect (investigative response) and those that also investigated whether children and families were in need of support services (differential response). The result showed that districts with "differential response" had a lower proportion of referrals investigated, but a higher proportion of cases that were substantiated as neglect (substantiation). This means that fewer cases were investigated when "differential response" was used, but that, of those cases investigated, fewer were dismissed. A Norwegian study from 2015 found that there are variations in dismissal rates between different CPS in different municipalities, the study does not explain why (Ellingsen, 2015).

A comparison of Sweden and Great Britain (Cocozza, Gustafsson \& Sydsjö, 2010) showed that there were no substantial disparities between the percentage of dismissals from services that are organized for overall investigation of children's and families' needs (Sweden) and that of services that are primarily organized to analyse individual events where neglect is suspected (Great Britain). 
Hayes and Spratt (2009) pointed out that, during the past 15 years when Great Britain has expressed the objective of changing child welfare organization from being focused on identifying neglect to focusing more on the needs of children and families, the increasing amount of cases had led to low thresholds for initiating needs analyses, but that the threshold for opening an investigation with the idea of identifying neglect (investigative response) had, in fact, increased. The authors argue that this has led to the closing of a number of serious cases without investigation while support services determined through needs analysis are primarily reserved for the less serious cases.

To avoid a scenario in which one individual social worker's assessments have unfortunate influence on the quality of decisions, different variants of group-based (consensus-based) organization of the decision-making process are used. One study (Nouwen, Decuyper \& Put, 2012), however, showed that merely gathering social workers organizationally did not automatically strengthen the quality of reasoning and decisions because group thinking and conformity was easily developed during discussions and analyses.

The results on organization characteristics are summarized in Table 5.

- $\quad$ Insert Table 5 here

\section{Discussion}

The main finding in the studies that dealt with case characteristics and thresholds for dismissal was that certain case characteristics were deemed significant to whether cases were dismissed or investigated. The most important case characteristics included: the families' ethnic background, characteristics of the children (e.g. gender and age), substance abuse among the parents and the parents' socioeconomic status. These findings have primarily come forth through American and Canadian register studies, in which a large number of cases have been included in the analyses. This means that the study conclusions are robust in that the likelihood that coincidence or bias has influenced the selection is very small. A drawback of these register studies is that the analyses involve few variables. This means that most of the variables that should be included when 
drawing conclusions according to the DME model (Figure 1) have not been included in some studies. Therefore, it is difficult to conclude which case factors, relatively speaking, are weighed most heavily when child welfare makes decisions.

Both gender and age had a significant correlation to dismissal in the USA. Cases involving boys were dismissed to a more substantial degree than those involving girls. One possible explanation for this may be tied to traditional gender stereotypes. However, no professional foundation exists for a difference in thresholds, since caregiver violence is equally harmful to boys as it is to girls. When it comes to age, it was also found that cases involving children aged 6 to 10 were dismissed to a lesser degree than cases related to both younger and older children. The threshold for intervention was thus higher for babies and toddlers or youth in the families that had been reported. The reason for this is hard to say, however, in regards to the oldest ones, perhaps there are fewer services available. Another explanation could be that the consequences of poor care may not be as detectable until the child reaches school age, where it is more easily discovered by teachers, for example.

Substance abuse is a case characteristic that appears to involve low thresholds for intervention across studies. This may be tied to the parents' care capacity and presence as parents, along with their capacity to keep up with the children at school and otherwise.

Socioeconomic status appears to be a central threshold across studies. In cases where the family was marginalized and faced socioeconomic challenges, a case was more frequently opened than when the family was financially secure and had a higher socioeconomic status, regardless of the severity. This indicates that the threshold for intervention is lower for families with low income and educational level. In Norway, the significance of socioeconomic factors in is less clear

In some of the studies that dealt with the significance of social workers in the quality of child welfare decisions, it was documented that the child's viewpoint often disappeared. Several studies uncovered different influential factors in the social workers' assessments of case severity; personal 
characteristics of the social workers, the social workers' attitudes on placing children outside the home and the caseworkers' stress level affected the assessments, in addition to competence levels among the social workers.

Many of these studies were so-called vignette studies. A vignette study consists of a description of one or more fictitious situations or cases that social workers are asked to assess and take a position on, indicating what types of decisions they would recommend based on the available information. This type of study is well suited to comparing the assessments and decisions of different groups of social workers. The results of these studies demonstrate that social workers' assessments of risk factors, their recommendations for services and the severity of a case vary. There is somewhat considerable variation between individual caseworkers, caseworkers from different offices and caseworkers from different countries. Several of these studies concluded that caseworkers' personal viewpoints and attitudes influence their decisions and that case characteristics explain child welfare decisions to a small degree. It may be a potential threat to the quality of child welfare decisions if similar cases are assessed quite differently by caseworkers. However, there are limitations to the vignette study methodology, meaning that these results may have limited transfer value for actual cases. Foremost among these is the fact that vignettes are best suited to studying decisions made by individuals (Evans, Roberts \& Keeley, 2015). Decisions that close out a child welfare investigation, however, are generally left to the assessment of several caseworkers in collaboration.

When it comes to the studies that looked at organization, available services and resources were most significant to whether a case was dismissed or further investigated. Factors of the individual offices appear to be most important with regard to dismissal versus investigation; e.g., resources, organizational culture, framework limitations, personnel and so on. The individual caseworker seems to be less important than the type of culture that exists at the organizational level. 
If one wishes to develop the procedural aspects of referral management and investigative processes, it is also imperative to work on organizational development.

\section{Conclusion}

There are a few case characteristics that reliably predict that a CPS investigation will be initiated. These are (i) that the report contains information about parental substance abuse and (ii) that the report contains information about serious physical abuse with visible injuries to the child. There seem to be high agreement between social workers that these are concerns that warrant further investigation. When serious physical harm or sexual abuse is substantiated they also predict further action and provision of services. Variables that predict decisions about provision of services in cases of neglect or psychological abuse vary between studies. In such cases, decisions seem to be partly dependent on social workers judgement of what constitutes risk. It is not fully known which social worker related factors that contribute to differences in judgement and decision making.

Studies have however linked social worker bias to race, gender, personality type and different stereotypical perceptions of children and families in need. There are substantial differences between various agencies and organizations with respect to factors that determine decision-making in Child Protection investigations. Some studies have examined the significance of the individual social worker's assessment for the outcomes of decisions, viewed in relation to organizational and case factors. These do not provide any clear conclusions. Because there is substantial variation in the types of problems and background of child welfare cases, it is methodologically challenging to design studies that capture all possible variables associated with case factors, social workers and organizational factors. However, multi-level analyses of the types of variables that are most significant to case outcome conclude that caseworker assessments are mediated by organizational factors and that variations in decision making are better explained by characteristics of the child 
welfare organization than by characteristics of the social worker (Font \& Maguire-Jack, 2015). Although many studies discuss differences in culture and legislation as an important factor that may explain differences in decision making regarding CPS cases in different countries, we found no studies that compare such differences on a case level. Therefore, we can not conclude whether or not external factors affect decisions over and above factors related to case, social worker and organizations.

Funder. The Norwegian Directorate for Children, Youth and Family Affairs. 
Baumann, D J , Dalgleish, L , Fluke, J , \& Kern, H (2011) The decision-making ecology. Washington, DC: American Humane Association

Berger, L. M., McDaniel, M. \& Paxson, C. (2005). Assessing parenting behaviors across racial groups: Implications for the child welfare system. Social Services Review, 79, 653-688.

Burton, S. (2009). The oversight and review of cases in the light of changing circumstances and new information: how do people respond to new (and challenging) information? National Children's bureau, Storbritannia.

Cocozza, M., Gustafsson, P.A., \& Sydsjö (2010). Child protection in a family-service organisation What is the outcome for maltreated children? Children and Youth Services Review, 32 (7), 922-928. Doi: http://dx.doi.org/10.1016/j.childyouth.2010.03.003

Cross T.P., \& Casanueva C. (2008). Caseworker judgments and substantiation. Child Maltreatment. 14(1):38-52. doi: 10.1177/1077559508318400.

Dettlaff, A.J., Rivaux, S.L., Baumann, D.J., Fluke, J.D., Rycraft, J.R., \& James, J. (2011). Disentangling substantiation: The influence of race, income, and risk on the substantiation decision in child welfare. Children and Youth Services Review, 33 (9), 1630-1637. Doi: http://dx.doi.org/10.1016/i.childyouth.2011.04.005.

Ellingsen, D., Linn Andersen, L., \& Viblemo, T.E. (2015). Terskler i barnevernet. Oslo: Arbeidsforskningsinstituttet.

Evans, S.C., Roberts, M.C., Keeley, J.W. et al. (2015). Vignette methodologies for studying clinicians' decision-making: Validity, utility, and application in ICD-11 field studies. International Journal of Clinical and Health Psychology. 15 (2), 160-170. Doi: https://doi.org/10.1016/j.ijchp.2014.12.001 Font, S. A., \& Maguire-Jack, K. (2015). Decision-making in child protective services: influences at multiple levels of the social ecology. Child abuse \& neglect, 47, 70-82.

Fallon, B., Ma, J., Black, T., \& Wekerle, C. (2011). Characteristics of young parents investigated and opened for ongoing services in child welfare. International Journal of Mental Health and Addiction, 9(4), 365-381.

Fluke J.D., Baumann D.J., Dalgleish L.I., Kern H.D. (2014) Decisions to Protect Children: A Decision Making Ecology. In: Korbin J., Krugman R. (eds) Handbook of Child Maltreatment. Child Maltreatment (Contemporary Issues in Research and Policy), vol 2. Springer, Dordrecht. Doi:

https://doi.org/10.1007/978-94-007-7208-3_25

Hayes, D., \& Spratt, T. (2009). Child welfare interventions: Patterns of social work practice. British Journal of Social Work, 39(8), 1575-1597.

Helm, D., \& Roesch-Marsh, A. (2010) Ecology of judgement in child welfare and protection. Seminar held 19.10.10 at Stirling University, URL: https://www.iriss.org.uk/sites/default/files/2016-07/irissecology-of-judgement-report-2011-07-13.pdf 
Higgins, M. (2017). Child Protection Social Work in England: How Can It Be Reformed?, The British Journal of Social Work, Volume 47, (2), 293-307, https://doi.org/10.1093/bjsw/bcv078

Howell, M. L. (2010). Intake decision-making in child protective services: Exploring the influence of decision-factors, race, and substance abuse. Dissertation Abstracts International Section A: Humanities and Social Sciences, 71(2-A), 715.

Janczewski, C. E. (2015). The influence of differential response on decision-making in child protective service agencies. Child abuse \& neglect, 39, 50-60.

Jedwab, M., Benbenishty, R., Chen, W., Glasser, S., Siegal, G., \& Lerner-Geva, L. (2015). Child protection decisions to substantiate hospital child protection teams' reports of suspected maltreatment. Child abuse \& neglect, 40, 132-141.

Jent, J. F., Eaton, C. K., Knickerbocker, L., Lambert, W. F., Merrick, M. T., \& Dandes, S. K. (2011). Multidisciplinary child protection decision making about physical abuse: Determining substantiation thresholds and biases. Children and youth services review, 33(9), 1673-1682.

Johnson, E. P., Clark, S., Donald, M., Pedersen, R., \& Pichotta, C. (2007). Racial disparity in Minnesota's child protection system. Child Welfare, 86(4), 5.

Jones, A. S. (2015). Implementation of differential response: A racial equity analysis. Child abuse \& neglect, 39, 73-85.

Jud, A., Fallon, B., \& Trocmé, N. (2012). Who gets services and who does not? Multi-level approach to the decision for ongoing child welfare or referral to specialized services. Children and Youth Services Review, 34(5), 983-988.

Juul, R. (2010). Barnevernets undersøkelser av bekymringsmeldinger: Diskursive praksisformer og barneperspektiver i den kommunale barneverntjeneste, og konsekvenser i forhold til barna. [Child welfare investigations of concern messages: Discursive practices and child perspectives in the municipal child welfare service, and consequences in relation to the children]. Trondheim: NTNU (Doctoral Thesis)

Keddell, E. (2011). Reasoning processes in child protection decision making: Negotiating moral minefields and risky relationships. British Journal of Social Work, 41(7), 1251-1270.

Kirkman, E., \& Melrose, K. (2014). Clinical Judgement and Decision-making in Children's Social Work: An Analysis of the'front Door'System. London: Department for Education.

Lazar, A. (2006). Determinants of child protection officers' decisions in emergency situations: An experimental study. In Child and Youth Care Forum (Vol. 35, No. 3, pp. 263-276). Springer US.

LeBlanc, V. R., Regehr, C., Shlonsky, A., \& Bogo, M. (2012). Stress responses and decision making in child protection workers faced with high conflict situations. Child abuse \& neglect, 36(5), 404-412.

Lee, S. J., Sobeck, J. L., Djelaj, V., \& Agius, E. (2013). When practice and policy collide: Child welfare workers' perceptions of investigation processes. Children and Youth Services Review, 35(4), 634-641.

Lurie, J., Kvaran, I., Tjelflaat, T., Sørlie,H.E. (2015) Barneverntjenestens arbeid med barnevern- 
undersøkelser i Midt-Norge. Rapport 4/2015. Trondheim:NTNU RKBU-Midt

Miller-Perrin, C. L., \& Miller, R. D. (2012). Child Maltreatment: An Introduction. $3^{\text {rd }}$ edition. USA: Sage Publications.

Moraes, S., Durrant, J., Brownridge, D. and Reid, G. (2005) 'Professionals' decisionmaking in cases of physical punishment reported to child welfare authorities: Does family poverty matter?', Child and Family Social Work, 11(2), pp. 157 - 69. doi: 10.1111/j.1365-2206.2006.00408.x

Munro, E. (2011) The Munro review of child protection: Final report. A child centered system. Department for Education. Downloaded from:

https://www.gov.uk/government/uploads/system/uploads/attachment_data/file/175391/MunroReview.pdf

Norwegian Board of Health Supervision (2012). Oppsummering av landsomfattende tilsyn i 2011 med kommunalt barnevern - undersøkelse og evaluering. [Summary of nationwide supervision in 2011 with municipal child welfare services - survey and evaluation]. Oslo: Helsetilsynet [Norwegian Board of Health Supervision].

Nouwen, E., Decuyper, S., \& Put, J. (2012). Team decision making in child welfare. Children and Youth Services Review, 34, 2101-2116. Doi: 10.1016/ j.childyouth.2012.07.006.

Office of the Auditor General of Norway (2012) Riksrevisjonens unders økelse om det kommunale barnevernet og bruken av statlige virkemidler. [OAG's survey on municipal child welfare and the use of government instruments]. Document 3:15. Oslo: Riksrevisjonen [Office of the Auditor General of Norway].

Östberg, F. (2010). Bedömningar och beslut: Från anmälan till insats i den sociala barnavården. [Assessments and decisions: From notification to intervention in social child welfare]. Stockholm University, Faculty of Social Sciences, Department of Social Work. PhD avhandling.

Platt, D. (2006) 'Threshold decisions: How social workers prioritise referrals of child concern', Child Abuse Review, 15), 4 - 18. Doi: 10.1002/car.929

Platt, D. and Turney, D. (2013). 'Making threshold decisions in child protection: a conceptual analysis', British Journal of Social Work, 44 (6):1472-1490. doi:10.1093/bjsw/bct007

Proctor, S., \& Azar, S. (2012). The effect of parental intellectual disability status on child protection service worker decision making. Journal of Intellectual Disability Research, 57(12), 1104-1116. doi: 10.1111/j.1365-2788.2012.01623.x

Rivaux, S., James, J., Wittenstrom, K., Baumann, D., Sheets, J., Henry, J., \& Jeffries, V. (2008). The intersection of race, poverty, and risk: Understanding the decision to provide services to clients and to remove children. Child Welfare, 87, 151-168.

Scannapieco, M., \& Connell-Carrick, K. (2005). Focus on the first years: Correlates of substantiation of child maltreatment for families with children 0 to 4. Children and Youth Services Review, 27, 13071323. DOI: $\underline{10.1016 / \text { j. childyouth.2005.01.005 }}$

Schreiber, J.C., Fuller, T., \& Paceley, M.S. (2013). Engagement in child protective services: Parent 
perceptions of worker skills. Children and Youth Services review, 35 (4), 707-715. Doi: https://doi.org/10.1016/j.childyouth.2013.01.018

Steen, J. A., \& Duran, L. (2014). Entryway into the child protection system: The impacts of child maltreatment reporting policies and reporting system structures. Child abuse \& neglect, 38(5), 868874.

Stokes, J., \& Taylor, J. (2014). Does type of harm matter? A factorial survey examining the influence of child neglect on child protection decision-making. Child care in practice, 20(4), 383-398.

Trocmé, N., Knoke, D., Fallon, B., \& MacLaurin, B. (2008). Differentiating between substantiated, suspected, and unsubstantiated maltreatment in Canada. Child Maltreatment.

Tufford, L., Bogo, M., \& Asakura, K. (2015). How Do Social Workers Respond to Potential Child Neglect?. Social Work Education, 34(2), 229-243.

Vis, S.A., Storvold, A., Skilbred, D., Christiansen, $\varnothing$., Andersen, A. (2014) Statusrapport om barnevernets undersøkelsesarbeid - høsten 2014. Troms $\varnothing:$ RKBU Nord

Wilkins, D. (2013). Balancing risk and protective factors: How do social workers and social work managers analyse referrals that may indicate children are at risk of significant harm. British Journal of Social Work, bct114.

Williams, G., Tonmyr, L., Jack, S. M., Fallon, B., \& MacMillan, H. L. (2011). Determinants of maltreatment substantiation in a sample of infants involved with the child welfare system. Children and Youth Services Review, 33(8), 1345-1353. 